\title{
Brine treatment, smoking and storage techniques: their effects on the microbial quality of smoked mackerel.
}

\author{
Eyabi Eyabi G. D \\ Research Station for Fisheries and Marine Science of the Institute \\ of Agriculture Research for Development (IRAD) \\ PMB 77 Limbe, Cameroon
}

Hanson S. W. and Barlow P. J.

University of Lincolnshire and Humberside, School of Applied Sciences and Technology Grimsby, England.

\begin{abstract}
Sample of Atlantic Mackerel (Scomber scombrus) were treated with $80^{\circ}$ brine for 2 hours with slight agitation while untreated fish served as control. Both treated and untreated fish were loaded in a Torry Afos Mini Kiln set at $50^{\circ} \mathrm{C}$. The temperature was raised to $80^{\circ} \mathrm{C}$ after one hour and maintained at this temperature throughout the smoking process.

Samples of treated and untreated fish (U8 and B8) were removed after 8 hours of smoking and the last batch removed at the end of 16 hours smoking (U16 and B16). Analyses for growth, identification and coverage of fish surface with mould and for sensory attributes of discoloration, off odours, brittleness (texture) and personal preference were carried out for freshly smoked and stored samples. Samples for storage were packaged in clear polythene and stored in an environmental cabinet.
\end{abstract}

\begin{abstract}
Bringing and smoking time retarded mould growth, controlled discoloration, off odour development, softening of the fish and positively affected personal preference.

Penicillium sp was identified as the incriminated species.

Keywords: Hot smoking, traditional smoking, water activity, brine strength, number of fish with mould growth and mean percentage coverage.
\end{abstract}

\section{Introduction}

Traditional fish smoking (hot smoking)+ is an important, one reason being that over $70 \%$ of artisanal fish landings in Cameroon (artisanal fishing contributes an estimated $75 \%$ of total national production) are converted to smoked/ dried productions. In addition, smoked fish occupies an important place in the culinary habits of Cameroonians, contributing nearly $45 \%$ of animal proteins (Robinson and Crispoli, 1984).

Regrettably, traditional smoked fish are generally of variable quality and sometimes of poor quality, essentially manifested by mould growth a few days on storage. Mould growth affects not only acceptability, but also chemical and nutritional quality. There is the need to identify parameters of acceptability for smoked fish, to develop techniques for controlling and analysing mould growth and to establish the link between acceptable levels of preservatives and the levels that will give the required protection.

There is also need to establish the relationship between raw fish quality, smoke process technology, packaging and storage conditions and the microbial quality of hot smoked fish.

Some work has been carried out on the effects of treatment with salt and other preservatives (vinegar, BHT, BHA, citric acid, potassium sorbate etc.) smoking and the use of packaging on the quality of smoked fish, notably that recorded by Eyabi Eyabi and Ningo (1996), Eyabi Eyabi (1988), FAO (1981) and Bostock, Walker and Wood (1987). Salting and smoking after affect microbial growth through their effects on water activity (AW) ++ , the high temperatures of hot smoking and the antimicrobial properties of wood smoke. These effects also have been noted in traditionally smoked long neck croaker (pseudotolithus typus) by' Eyabi Eyabi (1993). Also, Zakhia, Coulibaly, Coulibaly and Cisse (1998) noted that vinegar and vinegar plus salt mixture delayed mould appearance on dried fish and this led to increased shelflife from 2 to 6 months.

The effects of salting and smoking time on sensory qualities partly relates to the moisture content/water actuity. For freshly smoked fish, salting and smoking time are most likely to influence flavour, texture and personal preference to mention, while on storage, they are discernible by measurements or perceptions of flavour, texture, colour and personal preference. These observations have been recorded by Eyabi Eyabi, 1988.

\section{Objectives}

The objectives of this study are to evaluate the effects of brining and smoking time on mould growth and organoleptic quality of freshly smoked and stored fish

\section{Materials and Methods}

\section{Samples of ATLANTIC Mackerel} (Scomber scombrus) caught in the English Channel were supplied to the Laboratory in Grimsby - England in refrigerated transport. Fish were chilled stored to be processed the next day. Atlantic mackerel was chosen for this study as a typical fatty fish that is popularly used for the production of smoked fish in many parts of the world.

2. The salt for brining was of the quality and grain bought from the 
supermarket in Grimsby.

3. The clear polythene bags which provided air/moisture barrier packaging were also bought locally in Grimsby.

4. An environmental cabinet was used for storage $\left(30^{\circ} \mathrm{C} \pm 2.75-85 \% \mathrm{RH}\right)$.

\section{Methods}

One hundred and thirty two (132) fish collected from the chill store were gutted through the back, washed thoroughly to remove blood, dirt, entrails including hepatopancrease, gills, heart, liver and gut before dividing into 4 treatment groups as follows

Thirty fish to be smoked for 8 hours (U8), 30 fish to be brined and smoked for 8 hours (B8), 30 fish to be smoked for 16 hours (U16) and 30 fish to be brined and smoked for 16 hours (B16) while the remaining 12 fish were frozen at $-60^{\circ} \mathrm{C}$ to be used as control for chemical and nutritional analysis reported in another paper (Eyabi Eyabi, Hanson and Barlow, 2001).

Sixty fish (U8 and B8) were kept in a chill store, while 60 fish (B8 and B16) were brined in a salt solution of $80^{\circ}+++$ for 2 hours with limited agitation now and again.

After brining, both brined and unbrined samples were placed in a Torry Afos Mini Kiln set at an initial temperature at $50^{\circ} \mathrm{C}$. After one hour, the temperature was raised to $80^{\circ} \mathrm{C}$ and maintained at this level throughout the rest of the "hot smoking process". Thirty unbrined (U8) and $30-$ brined (B8) fish were removed from the oven after 8 hours of smoking and allowed to cool. The last batch of 30 unbrined (U16) and 30-brined (B16) were removed after 16 hours smoking.

On cooling to room temperature, 24 fish were randomly selected from the 30 fish of each treatment group on basis of wholesomeness and the balance of 6 fish were frozen stored at $-60^{\circ} \mathrm{C}$ as a safeguard. The 24 fish from each treatment group were divided into 6 fish for each of the storage intervals $(0,4$, and 12 weeks). The 6 fish were further divided into two groups of 3 fish each. The first group was used for chemical analysis reported in another paper (Eyabi Eyabi, Hanson and Barlow 2000) and for organoleptic quality while the second group was used to measure mould growth. Samples for storage were wrapped in clear polythene and stored in an environmental cabinet set at $30\left(+2^{\circ} \mathrm{C}\right)$ and $75 \%$ to $85 \%$ Relative Humidity throughout the storage period. The number of fish with visible mould growth and mean percentage coverage was measured for the same 12 samples throughout the storage period $(0,2,4,6,8$, 19 and 12 weeks).

Organoleptic analyses were determined for attributes of discoloration, brittleness, off-odours and personal preferences on a 5 point hedonic scale by a panel of 12 judges for freshly smoked and stored samples $(0,4,8$, and 12 weeks).

In order to identify moulds growing on stored samples, mouldy growth on fish surface was scrapped off with sterile (wire) loop and inoculated on several slopes of sabourand and agar supplemented with chloramphenicol $(0.05 \mathrm{mg} / \mathrm{ml})$. Cultures were inoculated at $28^{\circ} \mathrm{C}$ and examined for gross and microscopic morphology. Microscopic morphology was studied on slide culture. Species identification of fungal isolates was made by comparison with standard description by Raper and Flannel (1965) and Raper and Thorn (1949).

\section{Statistical analysis}

Organoleptic analyses and mould growths were measured on 12 samples ( 3 fish for each treatment). In order to determine treatment differences due to brining and smoking time, Analysis of Variance and Duncans Multiple Range Test (DMRT) were applied.

Table 1: Moisture content and water activity data for fresh, smoked and stored

\begin{tabular}{cccc}
\hline Storage time in weeks & Sample Code & \% Water & Aw \\
\hline 0 & U8 & 32.9 & 0.95 \\
\hline & B8 & 32.4 & 0.81 \\
\hline & U16 & 16.2 & 0.81 \\
\hline B16 & 20.3 & 0.70 \\
\hline U8 & 28.5 & 0.85 \\
\hline B8 & 27.0 & 0.70 \\
\hline U16 & 20.7 & 0.84 \\
\hline 8 & B16 & 14.2 & 0.70 \\
\hline & U8 & 31.5 & 0.87 \\
\hline B8 & 27.9 & 0.75 \\
\hline U16 & 19.0 & 0.78 \\
\hline B16 & 14.5 & 0.69 \\
\hline U8 & 33.3 & 0.88 \\
\hline B8 & 25.1 & 0.73 \\
\hline & U16 & 24.0 & 0.82 \\
\hline B16 & 20.6 & 0.66 \\
\hline
\end{tabular}

*Each value is a mean of triplicate determinations. The mean coefficient of variation for water and AW are $13 \%$ and $11 \%$ respectively. Raw fish contained $71.7 \%$ water and had a AW of 0.98 


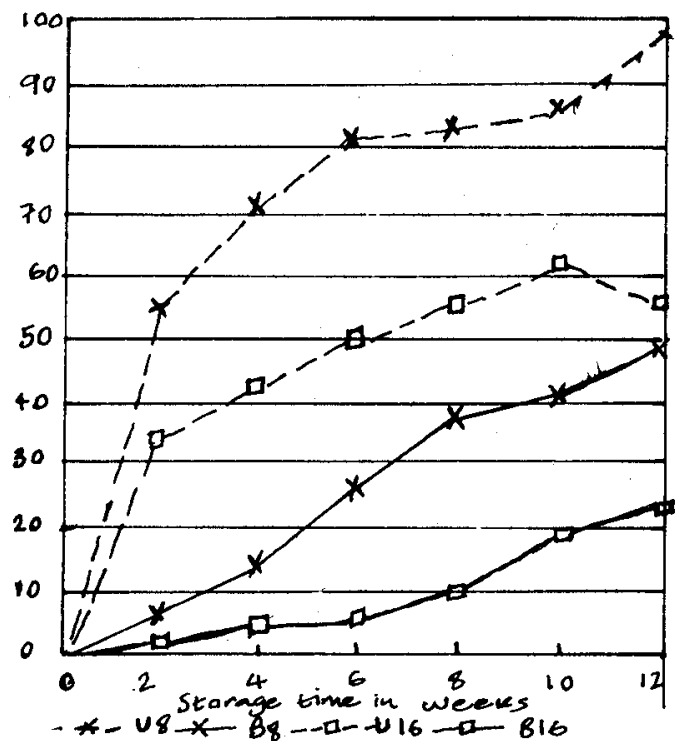

Figure I. Mean percentage coverege of fish surface during the storage of hot smoked mackerel

Discolouration score

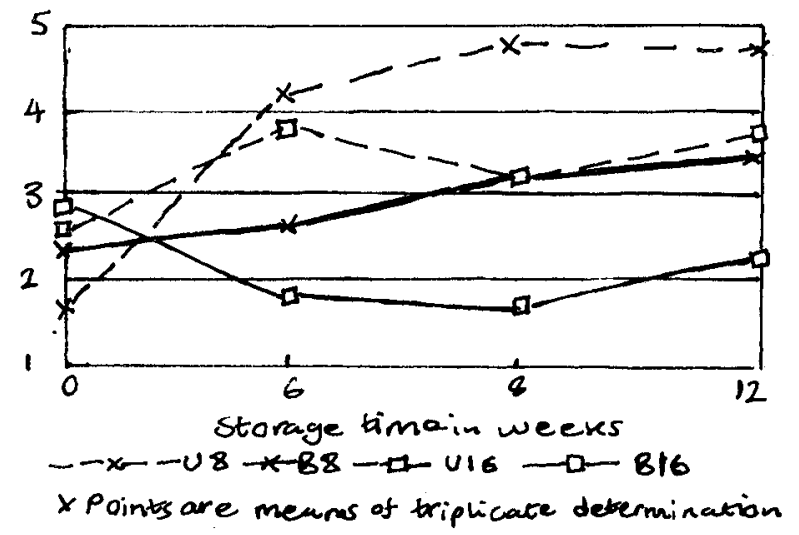

Figure III. Discolouration (taste panel scores) during storage of hot mackerel

activity. Brining and to a lesser extent smoking time significantly retarded discolouration $(\mathrm{P}<0.050 ; \xi=3.9,2.9,3.4$ and 2.2 for $\mathrm{U} 8, \mathrm{~B} 8, \mathrm{U} 16$ and $\mathrm{B} 16$ respectively. These effects were most visible between 4 and 12 week's storage with a climax at the end of 8 weeks storage. The steady increase in discolouration scores for treatments $B 8$ and $B 16$ between 8 and 12 weeks corresponded to the period where there was a corresponding steady increase of mould coverage especially for B16 (Tig. I and H).

Brittleness (Fig. IV) was significantly influenced by both prolonged smoking (greater degree of dehydration) and brining $(\mathrm{P}<0.05, \xi=1.7,2 ., 3.1,3.7$ for $\mathrm{U} 8$ $\mathrm{B} 8, \mathrm{U} 16$ and $\mathrm{B} 16$ respectively).

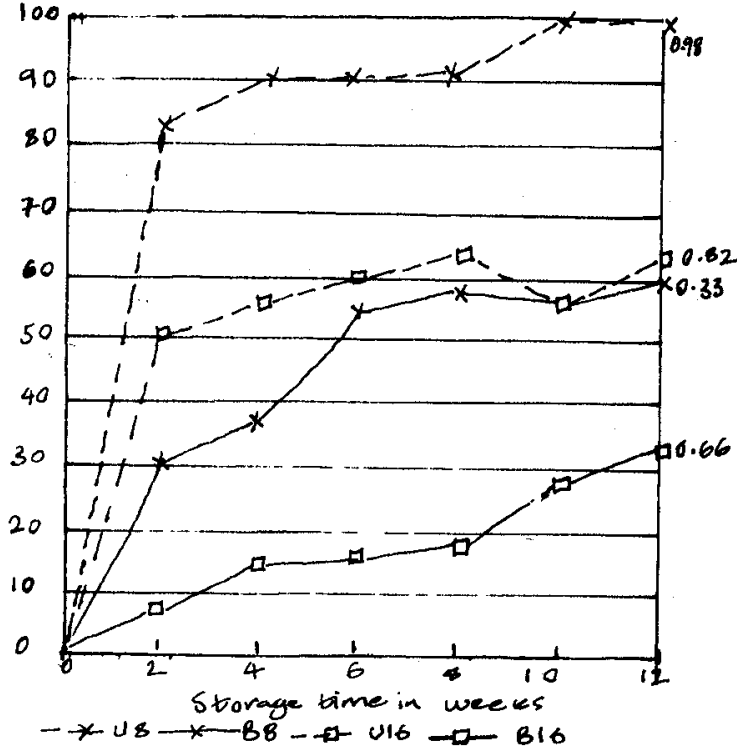

Figure II Percentage of fish with visible mould growth during the storage of hot smoked mackerel

Brittieness score

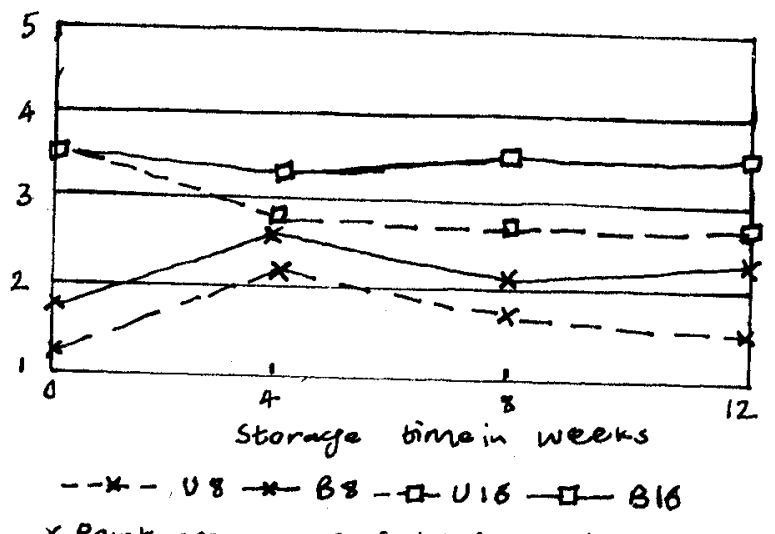

$x$ Points are manns of triplicate detemination

Figure IV. Brittleness (taste panel scores) during storage of hot smoked mackerel
Off-odours (Fig. V). Measurement indicated that brining and prolonged smoking significantly slowed down, its development $(\mathrm{P}<0.050, \xi=3.5,2.3,2.6$ and 1.8 for U8, B8, U16 and B16 respectively). The results are most indicative between 8 and 12 weeks storage. The most critical period in the development of off-odours was between 0 to 4 weeks for unbrined samples. Samples B8 showed a steady increase throughout storage while B16 virtually remained unchanged.

Personal preference (Fig. VI) Showed preference for treatment U8and B8 on freshly smoked samples. During storage, personal preference tended to decrease (5-1) as the discolouration and off-odour developed. The crucial factor determining personal preference appeared to be the growth of mould either directly through discoloration or indirectly through the development of off-odours. The latter was true of samples with shorter smoke treatment (U8, B8 (Fig. V and VI). The samples with longer smoke treatment had probably more of the smoke flavour that partially obscured off-odour.

\section{conclusions and recommendations}

Penicillum spp. was the prevalent species recorded on stored mackerel Brining and prolonged smoking inhibited mould growth possibly through their effects on water activity and also the presence of antimicrobial agents in wood smoke. 
off-odour score

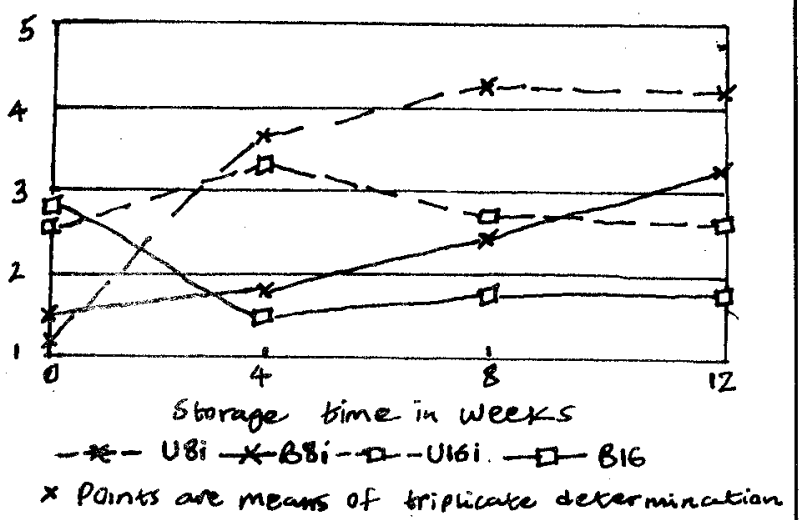

Figure $V$. Off-odour (taste panel scores) during storage of hot smoked mackerel
Preference scare

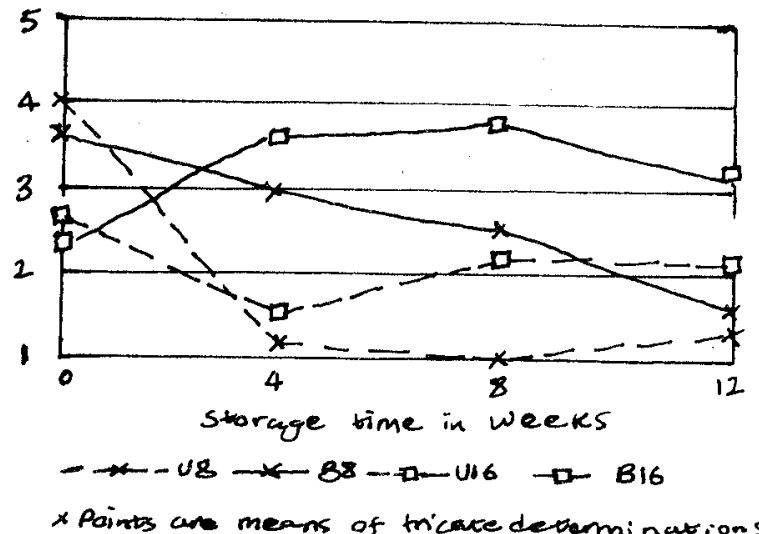

Figure VI. Preference scores during storage of hot smoked mackerel
The sensory measurements reflected mould growth with off-odours, personal preference on the decrease.

Whilst the level of salt and smoking time are being established in order to provide safe and stable products, it would be necessary on the one hand to consider acceptability, costs and health risks associated with the use of the salt and on the other, the use of food grade preservations to compliment or completely replace salt.

\section{References}

Bostock, T.W Walker, D.J. and Wood C.C. (1987) Reduction of losses in cured fish in the tropics-Guide for extension workers. Report G204 of the Tropical Development and Research Institute London.

Eyabi Eyabi, G.D. and Ningo G. (1986) Shelf life studies and packaging of smoke-cured Sardinella. In FAO. Fish Report No. 329: 150155.

Eyabi Eyabi, G.D. (1988) Lipid oxidation and other quality change during the storage of hotsmoked mackerel. M.Phil. Thesis. Humberside Polytechnic, school of Food, Fisheries and Environmental Studies, Grimsby-England.

Eyabi Eyabi, G.D. (1993) Effects of treatment and packaging on the storage quality of traditional smoked long-neck croaker (Pseudotolithus typus) in FAO. Rep. 467:58-64.
Eyabi Eyabi, G.D. (1998) Techniques for fish handling, marketing and smoking in Cameroon in FAO Fisheries Report 574.

Eyabi Eyahi, G.D. (2000) Brining, smoking and packaging on fish quality. Under edition for publication in Cameroon Academy of Science. Ref. $\mathrm{CAS} / 00 / 23$.

FAO (1981) The prevention of losses in cured fish in FAO Fisheries Technical Papers 129 pp 87

Lawel A.O. Talabi, S.O. and Sorinmade, S.O. (1986) Effects of salting on the storage and quality characteristics of smoked fillets of the Croaker (Pseudotolithus typus) Caught in Nigerian Waters in FAO Fisheries Report 329:251-262.

Raper K.B. and Thorn C. (1949) A manual of the Penicillia - Williams and Wikins Co Baltimore.

Raper K.B. and Fennel D.I. (1965) The germs Aspergillus Williams and Wikins Co., Baltimore,

Robinson M.A and Crispoli A: (1984) Estimation de la commercialisation et consommation de poison et produits de la peche dans la region du COPACE. COPACE/TECH/84.

Zakhia, N., Abdoulaye Coulibaly, Azziz Coulibaly, and O Troare Cisse. (1998) Use of some additives for improving preservation and quality of traditionally dried fish in Mali, in FAO Fisheries Report 574: 117-122.

\section{Appendices}

APPENDIX 1: Hot smoking - process in which fish is exposed to temperature $40-80^{\circ} \mathrm{C}$ at some stage during smoking, so that the protein is coagulated and the product can be eaten without further cooking. Traditional smoking is a more severe form of hot smoking with temperatures within the region $50-180^{\circ} \mathrm{C}$

APPENDIX 2: Water activity - describes the amount of water in a food available for microbial growth, enzymic and non- enzymic reactions. It can be measured as $\mathrm{P} / \mathrm{Po}+\mathrm{N} 2 /(\mathrm{N} 1+\mathrm{N} 2)$, Where $\mathrm{P}$ and $\mathrm{Po}$ are vapour pressure of solution and solvent and $\mathrm{N} 1+\mathrm{N} 2$ are the number of solute and solvent respectively.

APPENDIX 3: 80 brine strength - The amount of salt in a solution measured by density, in brineometer degree where $10 \cong 26 \mathrm{4g}$ salt'liter of water at $16^{\circ} \mathrm{c}$ and $80=(26.4 \times 8)=211.2 \mathrm{gm}$ salt/litre of water at the same temperature (16 ${ }^{\circ} \mathrm{C}$ ).

APPENDIX 4: (1) Number of fish with visible mould growth represented by the formular ni / $\mathrm{n}$ $x 100$ where $n i=$ number of fish in the treatment with evidence of mould attacked/growth and $n=$ total number of fish in the treatment.

Mean percentage coverage represented by the formual $\Sigma \mathrm{Mij} / \mathrm{n}$ where $\mathrm{M}=$ Surface covered by mould, $j=$ the number of replicates infested with mould and $n=$ the number of replicates in the treatment.

APPENDIX 5: Discolouration (1 for no discoloration to 5 for extreme discolouration), off-odors ( 1 for no off-odour to 5 for extreme off-odour), brittleness ( 1 for not brittle to 5 for extremely brittle) and personal preference ( 1 for bad to 5 for excellent) 